OPEN ACCESS

Edited by:

Muthuraman Muthuraman, University Medical Center of the Johannes Gutenberg University Mainz, Germany

Reviewed by: Florian Kattner Health and Medical University

Potsdam, Germany Jan Philipp Röer,

Witten/Herdecke University, Germany

${ }^{*}$ Correspondence:

Fabrice B. R. Parmentier fabrice.parmentier@uib.es

Received: 30 June 2021 Accepted: 11 August 2021 Published: 15 September 2021

Citation:

Leiva A, Andrés $P$ and

Parmentier FBR (2021) Aging Increases Cross-Modal Distraction by Unexpected Sounds: Controlling for Response Speed.

Front. Aging Neurosci. 13:733388 doi: 10.3389/fnagi.2021.733388

\section{Aging Increases Cross-Modal Distraction by Unexpected Sounds: Controlling for Response Speed}

\author{
Alicia Leiva ${ }^{1,2}$, Pilar Andrés ${ }^{1,2}$ and Fabrice B. R. Parmentier ${ }^{1,2,3 *}$ \\ ${ }^{1}$ Neuropsychology \& Cognition Group, Department of Psychology \& Research Institute of Health Sciences (iUNICS), \\ University of the Balearic Islands, Palma, Spain, ${ }^{2}$ Balearic Islands Health Research Institute (IdISBa), Palma, Spain, \\ ${ }^{3}$ Department of Psychology, University of Western Australia, Perth, WA, Australia
}

It is well-established that task-irrelevant sounds deviating from an otherwise predictable auditory sequence capture attention and disrupt ongoing performance by delaying responses in the ongoing task. In visual tasks, larger distraction by unexpected sounds (deviance distraction) has been reported in older than in young adults. However, past studies based this conclusion on the comparisons of absolute response times (RT) and did not control for the general slowing typically observed in older adults. Hence, it remains unclear whether this difference in deviance distraction between the two age groups reflects a genuine effect of aging or a proportional effect of similar size in both groups. We addressed this issue by using a proportional measure of distraction (PMD) to reanalyze the data from four past studies and used Bayesian estimation to generate credible estimates of the age-related difference in deviance distraction and its effect size. The results were unambiguous: older adults exhibited greater deviance distraction than young adults when controlling for baseline response speed (in each individual study and in the combined data set). Bayesian estimation revealed a proportional lengthening of RT by unexpected sounds that was about twice as large in older than in young adults (corresponding to a large statistical effect size). A similar analysis was carried out on the proportion of correct responses (PC) and produced converging results. Finally, an additional Bayesian analysis comparing data from cross-modal and uni-modal studies confirmed the selective effect of aging on distraction in the first and not the second. Overall, our study shows that older adults performing a visual categorization task do exhibit greater distraction by unexpected sounds than young adults and that this effect is not explicable by age-related general slowing.

Keywords: deviance distraction, aging, auditory distraction, cross-modal attention, oddball, attention capture

\section{INTRODUCTION}

The ability to filter out task-irrelevant stimuli to concentrate on a task at hand plays a fundamental role in efficient functioning. Yet, being entirely oblivious to task-irrelevant stimuli can be counterproductive. For example, the reader of this article may be using selective attention to help process the meaning of this text while filtering out nearby conversations, the noise of a passing car, or other extraneous stimuli. However, should the fire alarm suddenly go off, detecting such unexpected 
auditory stimulus would be of paramount importance to interrupt ongoing activities (reading) and modifying one's behavior in the service of a new goal (exiting the building). From an attentional perspective, this example illustrates the balance between selective attention (filtering out irrelevant stimuli) and change detection (allowing unexpected stimuli to break through attentional filters) mechanisms. Abundant research has evidenced the existence and neurological underpinnings of mechanisms capable of detecting the occurrence of stimuli violating predictions and capturing our attention in an obligatory manner (Schröger, 1996, 2007; Escera et al., 1998; Schröger and Wolff, 1998; Winkler, 2007; Wessel and Aron, 2013; Parmentier, 2014). While adaptive, such mechanisms present one downside: the interruption of ongoing cognitive activities yields a transient reduction in ongoing task performance which, when attention-capturing stimuli are truly irrelevant, amounts to distraction.

One class of stimuli repeatedly shown to grab attention are sudden changes (oddball stimuli) in a sequence of otherwise repeated or predictable (standard) sounds (see Parmentier, 2014, for a review). At the center of the present study is the finding that distraction by unexpected sounds is significantly greater in older than in young adults when the task at hand is visual (Andrés et al., 2006; Parmentier and Andrés, 2010; Leiva et al., 2015b, 2016), and not when it is auditory (Leiva et al., 2015a,b). Here, our primary aim was to re-evaluate the cross-modal studies to examine an issue prominent in the field of aging research, but which has been overlooked in past studies on aging and distraction by unexpected sounds: the role of baseline response speed. We used Bayesian statistics to re-analyze the data from four past studies and establish whether their conclusions remain valid when factoring out age-related variations in response speed. As a secondary aim, for completeness, we also performed a similar analysis on response accuracy. Finally, we contrasted these data with those from two past studies using uni-modal oddball tasks and confirmed that aging selectively affect distraction in the cross-modal oddball task.

\section{Distraction by Unexpected Sounds}

Task-irrelevant sounds unexpectedly deviating from a predictable sequence induce an orienting response characterized by specific electrophysiological responses and behavioral distraction (Schröger, 1996, 2005; Escera et al., 1998; Berti and Schröger, 2001; Horváth et al., 2008; Parmentier et al., 2008; Berti, 2013; Parmentier, 2014; Rosburg et al., 2018). This is typically studied in simple forced-choice categorization tasks involving taskirrelevant sounds (Escera et al., 1998; Pacheco-Unguetti and Parmentier, 2014; Parmentier et al., 2014, 2018), though it is not specific to that task and has been observed in others such as duration judgment, go-no go, visual matching, serial recall, or gap detection tasks (Berti and Schröger, 2001; Hughes et al., 2005; Bendixen et al., 2010; Li et al., 2013; Röer et al., 2015, 2017, 2018; Pacheco-Unguetti and Parmentier, 2016; Körner et al., 2017; Vachon et al., 2017; Volosin et al., 2017; Volosin and Horváth, 2020).

In cross-modal oddball tasks, target stimuli are typically visual, each preceded by a task-irrelevant sound which is repeated on most trials and unexpectedly replaced by a different sound on some trials. These unexpected changes typically entail longer response times (RT) and sometimes a small reduction in response accuracy (see Parmentier, 2014, for a review). This effect is thought to reflect the transient inhibition of motor actions (Wessel and Aron, 2013; Parmentier, 2016; Wessel, 2017; Vasilev et al., 2019, 2021; Wessel and Huber, 2019) and the involuntary shift of attention to and from the unexpected sound (Schröger, 1996; Parmentier et al., 2008). These behavioral manifestations are thought to reflect an adaptive interruption of ongoing actions, the assessment of whether a new action plan must be selected and, if not, the reactivation of the relevant task set (Corbetta and Shulman, 2002; Verbruggen et al., 2014; Wessel and Aron, 2017). Importantly, unexpected sounds distract because they violate the cognitive system's predictions, not because they are rare per se (Schröger et al., 2007; Parmentier et al., 2011; Volosin and Horváth, 2014; Schröger and Roeber, 2021). Consequently, distraction lessens or disappears when unexpected sounds are made predictable (e.g., Sussman et al., 2003; Horváth and Bendixen, 2012; Parmentier and Hebrero, 2013), but it appears immune to the predictability of our own behavior (Parmentier and Gallego, 2020).

\section{Aging and Distraction by Unexpected Sounds}

Several studies have examined distraction by unexpected sounds in young and older adults. In studies using uni-modal tasks, aging does not appear to modulate deviance distraction. While one study using an auditory duration discrimination task reported an age-related increase in distraction by rare and unexpected changes in pitch (Berti et al., 2013), a subsequent study using a larger sample found no difference between the two age groups (Leiva et al., 2015a). Using a similar task in children, young and older adults, Horváth et al. (2009) found no difference between young and older adults with respect to behavioral deviance distraction. Similar degrees of behavioral distraction were also observed in young and high-performing older adults (Getzmann et al., 2013).

In contrast to uni-modal studies, cross-modal oddball studies consistently show an age-related increase in distraction by unexpected sounds. Using a visual digit categorization task, Andrés et al. (2006); see Parmentier and Andrés, 2010, for a replication) reported a twofold increase in distraction in older compared to young adults as measured from RT. A study comparing the two age groups in uni-modal and cross-modal oddball tasks confirmed a selective effect of aging on distraction in the cross-modal task (Leiva et al., 2015b). Converging findings were also reported in a cross-sectional study comparing children, young and older adults with respect to deviance distraction, working memory capacity and response inhibition (Leiva et al., 2016). The exact origin of the selective effect of aging on deviance distraction in the cross-modal as opposed to uni-modal tasks has not clearly been identified yet. The cross-modal task differs from the uni-modal in that it involves attention crossing sensory boundaries, which has been hypothesized as a one contributor to the effect (Parmentier et al., 2008). Hence, one reasonable 
hypothesis is that aging selectively affects the deployment of attention across sensory modalities while within-modality shifts are relatively unscathed (Leiva et al., 2015b).

\section{The Present Study: Controlling for Age-Related Differences in Response Speed}

Evidence shows that, relative to a repeated and predictable sound, unexpected sounds distract participants from the task at hand and yield longer RT. Interestingly, when this task is visual, distraction is significantly larger in older than in young adults (Andrés et al., 2006; Parmentier and Andrés, 2010; Leiva et al., 2015b, 2016). However, one factor has been overlooked in these studies: the general slowing exhibited by older adults. Indeed, while these studies reported age-related differences in RT between unexpected and standard sound conditions, the baseline response speed of participants was not considered. In other words, one cannot rule out the possibility that this age-related increase of distraction may simply be a proportional effect.

It is well-established that variations in cognitive and response speed constitute a key general factor in accounting for age-related changes in memory and cognition (Shimamura, 1994). Gradual slowing is a well-documented hallmark of aging (Cerella, 1985; Rogers and Fisk, 1990; Salthouse and Meinz, 1995; Salthouse, 1996, 2000). Not surprisingly, older adults were overall slower than young adults in all four cross-modal studies reviewed above. Hence, before concluding that unexpected sounds selectively affect older adults in cross-modal oddball tasks, it is necessary to examine whether the proportional increase in RT in the unexpected sound condition relative to the standard condition is greater for older than for young adults.

Here, we reanalyzed the data from the four cross-modal oddball studies on aging (Andrés et al., 2006; Parmentier and Andrés, 2010; Leiva et al., 2015b, 2016) to test for an agerelated increase in distraction while controlling for baseline response speed. To examine this issue, we compared young and older adults using a proportional metric of distraction whereby distraction (RT unexpected - RT standard) was pitched against baseline response speed (RT standard). We then used Bayesian estimation on the combined data set to derive pointestimates and 95\% high density intervals (95\% HDI) of the mean difference in proportional distraction and its effect size. The hypotheses were simple: If the age-related difference in RTs between unexpected and standard sound trials reflect a genuine increase in distraction, then (1) we should find significant differences in proportional distraction effects between the two age groups and (2) Bayesian estimation should reveal credible value ranges for the age group difference in proportional distraction and its effect size that exclude zero. In contrast, if the agerelated increase in distraction reported in previous studies is a mere reflection of a proportional slowing of responses, then (1) we should find no difference between the two age groups when controlling for baseline response speed, and (2) Bayesian estimation should highlight zero as a credible value for the mean age-related difference in distraction and its effect size.

\section{METHODS}

We present here a brief description of the key methodological aspects of the four cross-modal oddball studies (Andrés et al., 2006; Parmentier and Andrés, 2010; Leiva et al., 2015b, 2016) relevant to our purpose. Our focus was on the comparison of the RT and response accuracy of young and older adults in oddball tasks in which standard and unexpected sounds were presented while participants performed a visual categorization task. Hence, from the study by Leiva et al. (2015b), we used data from the cross-modal condition, not the uni-modal condition. From the study of Andrés et al. (2006), we used the data from the sound blocks, not the silent blocks. From the study by Leiva et al. (2016), we selected the data from young and older adults, not that of children, in the cross-modal oddball task (not the working memory or response inhibition tasks). In all cases, the first standard trial after an unexpected sound trial was excluded from the analysis, for past work demonstrated that this trial is subject to residual distraction (Ahveninen et al., 2000; Roeber et al., 2003; Berti, 2008).

\section{Participants}

The sample included a total of 204 participants (148 females and 56 males) forming two age groups: 108 young adults $(M$ age $=21.62, S D=3.68)$ and 96 older adults $(M$ age $=67.11$, $S D=8.38$ ). We present in Table 1 (Panel A) a descriptive breakdown of age and sex per study. For an average effect size of $d=0.963$ (mean of the $d$ values for the effect of aging on deviance distraction in the four studies we are revisiting), the statistical power of a $t$-test for this sample size, a Type I error of 0.05, and a one-tailed hypothesis, the statistical power of our study was $>0.999$. Put differently, given our sample size, the minimum effect size affording a power of 0.95 was $d=0.463$.

\section{Stimuli and Procedure}

The cross-modal oddball task presented the same general structure in all four studies, though with small variations with respect to the exact stimuli, proportion of unexpected sound trials, number of test trials, duration of stimuli, interstimuli and inter-trial intervals. For clarity, we present a descriptive comparison of the task characteristics in Table $\mathbf{1}$ (Panel B). In all cases, the participants' task was to perform a binary categorization of a visually presented stimulus (a digit in three studies, a cartoon $\operatorname{dog}$ in one). A taskirrelevant sound preceded each visual target. The duration of the sounds, sound-to-target, target, and trial-to-trial intervals was fixed within each study and varied slightly across studies. In the majority trials (70-90\%, depending on the study), a $600 \mathrm{~Hz}$ sinewave tone served as the standard sound while unexpected sounds (white noise or environmental sounds) was used in the remaining trials. Participants were instructed to attend the visual task and endeavor to respond as quickly as possible while trying to make no error. All participants were tested individually in a sound attenuated laboratory. Sounds were presented through headphones with a level of approximately $75 \mathrm{~dB}$ SPL. 
TABLE 1 | (A) Demographic characteristics of the samples from the four studies we reanalyzed. (B) Key methodological characteristics of the tasks used in the four studies we reanalyzed.

A

\begin{tabular}{|c|c|c|c|c|c|c|}
\hline & \multicolumn{3}{|c|}{ Older } & \multicolumn{3}{|c|}{ Young } \\
\hline & $n$ & $\mathbf{F} / \mathbf{M}$ & $M$ age (SD) & $n$ & F/M & $M$ age (SD) \\
\hline \multicolumn{7}{|l|}{ Participants characteristics } \\
\hline Andrés et al., 2006 & 22 & $6 / 16$ & $67.95(8.88)$ & 22 & $7 / 15$ & $22.26(3.73)$ \\
\hline Parmentier and Andrés, 2010 & 20 & $6 / 14$ & $68.6(9.05)$ & 20 & $8 / 12$ & $21.75(3.28)$ \\
\hline Leiva et al., 2015b & 22 & $7 / 15$ & $63.86(5.61)$ & 22 & $3 / 19$ & $21.64(4.51)$ \\
\hline Leiva et al., 2016 & 32 & $8 / 24$ & $64.17(5.58)$ & 44 & $11 / 33$ & $20.66(3.67)$ \\
\hline Overall & 96 & $69 / 27$ & $67.11(8.38)$ & 108 & $79 / 29$ & 21.62 (3.68) \\
\hline
\end{tabular}

B

\begin{tabular}{|c|c|c|c|c|c|c|c|c|c|}
\hline \multirow[b]{2}{*}{ Study } & \multirow[b]{2}{*}{ Task } & \multirow[b]{2}{*}{$\mathrm{N}$ test trials } & \multirow[b]{2}{*}{$\begin{array}{l}\text { Proportion } \\
\text { unexpected } \\
\text { sound }\end{array}$} & \multicolumn{2}{|c|}{ Type of sound } & \multirow[b]{2}{*}{$\begin{array}{l}\text { Sounds' } \\
\text { duration } \\
\text { (ms) }\end{array}$} & \multirow[b]{2}{*}{$\begin{array}{c}\text { Sound to } \\
\text { target } \\
\text { interval (ms) }\end{array}$} & \multirow[b]{2}{*}{$\begin{array}{l}\text { Target } \\
\text { duration } \\
\text { (ms) }\end{array}$} & \multirow[b]{2}{*}{$\begin{array}{l}\text { Trial to trial } \\
\text { interval (ms) }\end{array}$} \\
\hline & & & & Standard & Unexpected & & & & \\
\hline \multicolumn{10}{|c|}{ Tasks characteristics } \\
\hline $\begin{array}{l}\text { Andrés et al., } \\
2006\end{array}$ & $\begin{array}{l}\text { Visual digit } \\
\text { categorization }\end{array}$ & 1,200 & 0.1 & $\begin{array}{l}600 \mathrm{~Hz} \\
\text { sinewave tone }\end{array}$ & $\begin{array}{l}60 \\
\text { environmental } \\
\text { sounds }\end{array}$ & 200 & 100 & 200 & 1,500 \\
\hline $\begin{array}{l}\text { Parmentier and } \\
\text { Andrés, } 2010\end{array}$ & $\begin{array}{l}\text { Visual digit } \\
\text { categorization }\end{array}$ & 1,200 & 0.1 & $\begin{array}{l}600 \mathrm{~Hz} \\
\text { sinewave tone }\end{array}$ & $\begin{array}{l}60 \\
\text { environmental } \\
\text { sounds }\end{array}$ & 200 & 100 & 200 & 1,500 \\
\hline $\begin{array}{l}\text { Leiva et al., } \\
2015 b\end{array}$ & $\begin{array}{l}\text { Visual digit } \\
\text { categorization }\end{array}$ & 1,440 & 0.2 & $\begin{array}{l}600 \mathrm{~Hz} \\
\text { sinewave tone }\end{array}$ & White noise & 150 & 150 & 400 & 2,200 \\
\hline $\begin{array}{l}\text { Leiva et al., } \\
2016\end{array}$ & $\begin{array}{l}\text { Left/right } \\
\text { categorization } \\
\text { of cartoon dog }\end{array}$ & 480 & 0.3 & $\begin{array}{l}600 \mathrm{~Hz} \\
\text { sinewave tone }\end{array}$ & White noise & 150 & 100 & 200 & 2,950 \\
\hline
\end{tabular}

\section{DATA ANALYSIS}

The analysis was twofold. First, to test for the age-related variation in distraction while controlling for performance in the standard condition, we reanalyzed the data from four studies (Andrés et al., 2006; Parmentier and Andrés, 2010; Leiva et al., 2015b, 2016) using a proportional measure of distraction (PMD). While our primary interest lied in the analysis of RT, we also implemented this metric for the proportion of correct responses (PC) for completeness. This measure simply consisted in calculating the ratio between distraction (difference between the standard and unexpected conditions) and performance in the standard condition such that positive PMD values can be interpreted as a proportional detrimental impact of unexpected sounds on performance:

$$
\begin{aligned}
& P M D_{R T}=\frac{\left(R T_{\text {unexpected }}-R T_{\text {standard }}\right)}{R T_{\text {standard }}} \\
& P M D_{P C}=\frac{\left(P C_{\text {standard }}-P C_{\text {unexpected }}\right)}{P C_{\text {standard }}}
\end{aligned}
$$

Since Shapiro-Wilk and Levene tests carried out on PMD for RT and proportions of correct responses in each study revealed numerous deviations from normality (which were not solved by log-transforming the data) and homoscedasticity, we used the non-parametric Mann-Whitney's statistic. Effect size is reported as the rank-biserial correlation $\left(r_{B}\right)$. For each comparison, we also report the Bayes Factor $\left(B F_{10}\right)$ to assess the credibility of the experimental hypothesis relative to that of the null hypothesis given the data. Values below $1 / 3$ or $>3$ are regarded as moderate or substantial support for the null and experimental hypotheses, respectively, while values below $1 / 10$ and 10 are regarded as strong evidence (Jeffreys, 1961; Lee and Wagenmakers, 2013; Dienes, 2014; Quintana and Williams, 2018). Bayes factors were computed using 1,000 iterations. The analysis was conducted using JASP (JASP Team, 2019), using the default normal prior (mean of zero, standard deviation of 0.707 ). In these analyses, the a priori experimental hypothesis was that distraction is greater in older than in young adults. For confirmation and examination of the coherence of the pattern of results across the four studies, we also conducted a 4 (Study) $\times 2$ (Age Group) Bayesian Analysis of variance (BANOVA) on $\mathrm{PMD}_{P C}$ and $\mathrm{PMD}_{R T}$. Plots were created using the ggstatsplot (Patil, 2021) and ggplot2 (Wickham, 2016) packages in $\mathrm{R}$ ( $\mathrm{R}$ Core Team, 2021).

Next, we analyzed the complete set of data using Bayesian estimation (Kruschke, 2013, 2015) to provide credible parameters estimates about the difference in PMD between young and older adults (Kruschke, 2013, 2015). This analysis was carried in R (R Core Team, 2021) using the BEST package (Kruschke and Meredith, 2018). Bayesian estimation takes a different approach 
TABLE 2 | (A) Statistical effect of aging on distraction in each study (asterisks highlight significant effects). (B) Results of the Bayesian ANOVAs on response accuracy and response times.

\begin{tabular}{|c|c|c|c|c|c|c|c|c|}
\hline \multicolumn{9}{|l|}{ A } \\
\hline Study & M young (SD) & M older (SD) & Older - Young & $w$ & $p$ & $r_{B}$ & $95 \% \mathrm{Cl} \mathrm{r}_{\mathrm{B}}$ & $B F_{10}$ \\
\hline \multicolumn{9}{|l|}{$\mathrm{PMD}_{\mathrm{PC}}$} \\
\hline Andrés et al., 2006 & $0.004(0.038)$ & $0.031(0.061)$ & 0.027 & 305 & 0.072 & 0.260 & {$[-0.023, \infty]$} & 1.920 \\
\hline Parmentier and Andrés, 2010 & $-0.001(0.031)$ & $0.027(0.056)$ & 0.028 & 265 & $0.040^{*}$ & 0.325 & {$[0.033, \infty]$} & $3.023^{*}$ \\
\hline Leiva et al., 2015b & $4.863 \times 10^{-4}(0.045)$ & $4.343 \times 10^{-4}(0.043)$ & $-5.2 \times 10^{-5}$ & 255 & 0.385 & 0.054 & {$[-0.232, \infty]$} & 0.328 \\
\hline Leiva et al., 2016 & $-0.007(0.017)$ & $0.012(0.040)$ & 0.019 & 889 & $0.024^{*}$ & 0.263 & {$[0.048, \infty]$} & $4.681^{*}$ \\
\hline \multicolumn{9}{|l|}{$\mathrm{PMD}_{\mathrm{RT}}$} \\
\hline Andrés et al., 2006 & $0.036(0.035)$ & $0.083(0.067)$ & 0.047 & 357 & $0.003^{\star}$ & 0.475 & {$[0.223, \infty]$} & $18.116^{\star}$ \\
\hline Parmentier and Andrés, 2010 & $0.028(0.033)$ & $0.080(0.056)$ & 0.052 & 326 & $<0.001^{*}$ & 0.630 & {$[0.411, \infty]$} & 33.999* \\
\hline Leiva et al., 2015b & $0.022(0.044)$ & $0.059(0.058)$ & 0.037 & 331 & $0.018^{*}$ & 0.368 & {$[0.096, \infty]$} & $3.601^{*}$ \\
\hline Leiva et al., 2016 & $0.030(0.039)$ & $0.054(0.047)$ & 0.024 & 931 & $0.008^{\star}$ & 0.322 & {$[0.112, \infty]$} & $3.455^{\star}$ \\
\hline \multicolumn{9}{|l|}{ B } \\
\hline Models & & $B F_{10}$ & & & Error \% & & & Best $M / M$ \\
\hline \multicolumn{9}{|l|}{$\mathrm{PMD}_{\mathrm{PC}}$} \\
\hline Age Group & & 25.149 & & & 1.420E-07 & & & Best \\
\hline Study + Age Group & & 7.371 & & & 1.416 & & & 0.293 \\
\hline Study + Age Group + Study $\times$ & ge Group & 1.243 & & & 1.939 & & & 0.049 \\
\hline Study & & 0.346 & & & 1.636E-05 & & & 0.014 \\
\hline \multicolumn{9}{|l|}{$\mathrm{PMD}_{\mathrm{RT}}$} \\
\hline Age Group & & 236700 & & & $<0.001$ & & & Best \\
\hline Study + Age Group & & 48004.861 & & & 1.405 & & & 0.203 \\
\hline Study + Age Group + Study $\times$ & ge Group & 7308.905 & & & 1.930 & & & $<0.001$ \\
\hline Study & & 0.236 & & & 0.236 & & & $<0.001$ \\
\hline
\end{tabular}

BF values for the best model are high-lighted in bold.

to null hypothesis significance testing by calculating credible ranges of values for model parameters in the light of the empirical data (Kruschke, 2013; Kruschke and Liddell, 2018). The two key posterior parameters of interest were the point-estimate for the mean difference in PMD between the age groups and its effect size. For completeness, we also report the other posterior parameter (estimated standard deviation and normality of the difference). We used BEST's minimally informative default priors ("so that the prior has minimal influence on the estimation, and the data dominate the Bayesian inference," Kruschke, 2013 p. 576). Bayesian estimation reallocates credibility to the model's parameter in a way that best accommodates the empirical data. The posterior distribution's parameters were approximated using the Markov Chain Monte Carlo (MCMC) method, which generates a large sample of credible parameter values from the posterior distribution (using BEST's default size for this sample, or chain length, of 100,000). Credible intervals were calculated in the form of $95 \%$ HDI.

\section{RESULTS}

\section{Re-analysis of Past Studies Using PMD}

For clarity, we present the full list of statistical results for our first analysis in Table 2 (Panel A). As visible from these results, both non-parametric and Bayesian statistics supported our experimental hypothesis. Deviance distraction was significantly and credibly greater in older adults in all four studies for RT, and in two studies for the PC (while in the remaining two, the results were inconclusive). As visible in Table 2 (Panel B), the BANOVAs carried out on the combined sets of data provided strong $\left(\mathrm{PMD}_{P C}\right)$ and extreme $\left(\mathrm{PMD}_{R T}\right)$ evidence of the effect of aging on our proportional measures of distraction. While the evidence favored the conclusion that $\mathrm{PMD}_{P C}$ did not vary across studies, the $B F_{10}$ of 0.346 was inconclusive. In contrast, extreme evidence supported the absence of variation of $\mathrm{PMD}_{R T}$ across studies $\left(B F_{10}=0.003\right)$. Importantly, the results supported the absence of interaction between Study and Age Group: $B F_{10}=1.243 / 7.371=0.169$, and $B F_{10}=7308.905 / 48004.861=0.152$, for $\operatorname{PMD}_{P C}$ and $\operatorname{PDM}_{R T}$, respectively. The $\mathrm{PMD}_{P C}$ and $\mathrm{PMD}_{R T}$ values for participants in each age group are presented in Figure 1. The results can be summarized as follows. The strength of the evidence of the impact of aging on $\mathrm{PMD}_{P C}$ varied across individual studies but was strong in the combined data set. More importantly, the data clearly supported the hypothesis that aging increases $\mathrm{PMD}_{R T}$, with moderate to strong evidence in individual studies, and extreme evidence in the combined data set.

\section{Bayesian Estimation of Age-Related Difference in Deviance Distraction}

Bayesian estimation was carried out on $\mathrm{PMD}_{R T}$ and $\mathrm{PMD}_{P C}$ to generate credible posterior parameters given our data. All 


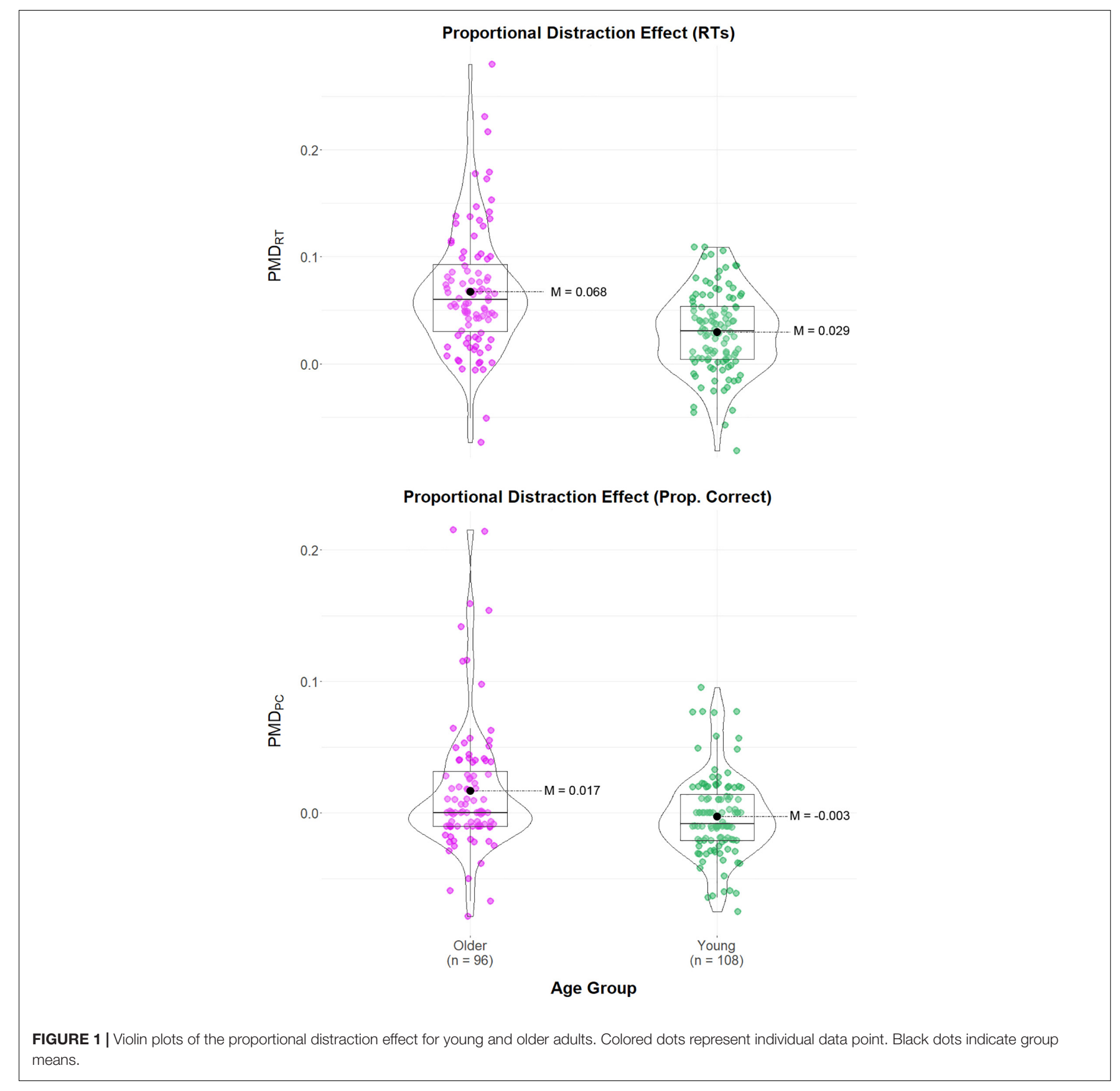

Gelman-Rubin diagnostic values were equal to 1 (confirming that convergence was reached), and the effective sample sizes varied between 18,579 and 62,535 (i.e., superior to 10,000 , the recommended value for accurate and stable estimates of the $95 \%$ HDI bounds, Kruschke, 2015).

We report the complete set of results for every parameter in Table 3 and focus here on the key relevant findings. For $\mathrm{PMD}_{R T}$, the point estimate for the mean difference between young and older adults was 0.035 (95\% HDI: 0.022-0.076), indicating that unexpected sounds produce a proportional increase of RT that is $3.5 \%$ greater in older than in young adults. The point estimate of the mean effect size for this difference was 0.8 (95\% HDI:
0.496-1.114), a large effect (Cohen, 1988; Lakens, 2013). Of importance, neither of the 95\% HDIs included the zero value. It is worth pointing out that this 95\% HDI does not overlap with a Region Of Practical Equivalence (ROPE) corresponding to a small effect size $(d=0.2)$ centered around zero (Kruschke, 2011, 2018). Hence, we can be confident that the effect of aging on $\mathrm{PMD}_{R T}$ is not equivalent to a null or a small effect.

The analysis of $\mathrm{PMD}_{P C}$ revealed results in the same direction as $\mathrm{PMD}_{R T}$. The point estimate for the mean difference between the two age groups was 0.010 , suggesting that, relative to their performance in the standard condition, older adults see their PC decrease by $1 \%$ more than young adults (95\% HDI: 0.002-0.019). 
TABLE 3 | Posterior parameters of the Bayesian Estimation of the effect of aging on distraction.

\begin{tabular}{|c|c|c|c|}
\hline Posterior parameter & Mean & 95\% HDI lower & 95\% HDI upper \\
\hline \multicolumn{4}{|l|}{$\mathrm{PMD}_{\mathrm{PC}}$} \\
\hline Molder & 0.005 & -0.002 & 0.012 \\
\hline$\mu$ Young & -0.005 & -0.010 & 0.000 \\
\hline$\sigma_{\text {Older }}$ & 0.026 & 0.019 & 0.034 \\
\hline$\sigma_{\text {Young }}$ & 0.022 & 0.017 & 0.027 \\
\hline \multicolumn{4}{|l|}{ Older - Young } \\
\hline$\mu$ & 0.010 & 0.002 & 0.019 \\
\hline$\sigma$ & 0.004 & -0.003 & 0.012 \\
\hline Normality $\left(\log _{10} v\right)$ & 0.441 & 0.240 & 0.643 \\
\hline Effect size & 0.419 & 0.074 & 0.760 \\
\hline \multicolumn{4}{|l|}{$\mathrm{PMD}_{\mathrm{RT}}$} \\
\hline$\mu_{\text {Older }}$ & 0.065 & 0.053 & 0.076 \\
\hline$\mu_{Y \text { Young }}$ & 0.029 & 0.022 & 0.037 \\
\hline$\sigma_{\text {Older }}$ & 0.051 & 0.040 & 0.062 \\
\hline$\sigma_{\text {Young }}$ & 0.036 & 0.030 & 0.042 \\
\hline \multicolumn{4}{|l|}{ Older - Young } \\
\hline$\mu$ & 0.035 & 0.022 & 0.048 \\
\hline$\sigma$ & 0.015 & 0.004 & 0.026 \\
\hline Normality $\left(\log _{10} v\right)$ & 1.183 & 0.621 & 1.837 \\
\hline Effect size & 0.800 & 0.496 & 1.114 \\
\hline
\end{tabular}

While this difference is small in absolute terms, its statistical effect size estimate was small to medium (0.419). The percentage overlap between the 95\% HDI (0.074-0.760) and ROPE (as defined as above) was 3.214 , suggesting that the probability that the effect size estimate is equivalent to a small effect is 0.032 .

\section{Supplementary Analysis: Effect of Aging on Cross-Modal vs. Uni-Modal Deviance Distraction}

The evidence above shows that aging increases deviance distraction in cross-modal tasks. As we pointed out earlier, past work using uni-modal auditory tasks contrasts with cross-modal studies in reporting no effect of age on deviance distraction. However, these conclusions were based on absolute differences in RT and did not consider age-related variations in response speed. Hence, as a supplementary analysis, we sought to confirm the selective effect of aging on deviance distraction by using $\mathrm{PMD}_{R T}$ to compare cross-modal and uni-modal (auditory) tasks. We included data from three of our cross-modal oddball studies (Andrés et al., 2006; Parmentier and Andrés, 2010; Leiva et al., 2016) and two past studies using an auditory uni-modal task (Leiva et al., 2015a,b). The uni-modal tasks of Leiva et al. (2015b) was identical to its cross-modal version but involved the parity categorization of an auditory (as opposed to a visual) digit. Note that because the study by Leiva et al. (2015b) compared cross-modal and uni-modal tasks withinparticipants, we could not include both in our analysis and opted to include the uni-modal data set. From the study by Leiva et al. (2015a), we used the data from the auditory task in which 84 participants ( 42 young adults, $M_{\text {age }}=20.9$, and 42 older adults, $M_{\text {age }}=62.8$ ) performed a binary tone duration judgment task in which $88 \%$ of trials involved a standard
$1,000 \mathrm{~Hz}$ tone, and the remaining $12 \%$ involved a deviant tone. The sample included in our analysis comprised of 150 young and 138 older adults. We conducted a 2 (Age group) $\times 2$ (task type: cross- vs. uni-modal) BANOVA on $\mathrm{PMD}_{R T}$. The results revealed strong evidence for the main effects of age group $\left(B F_{10}=12.087\right)$ and task type $\left(B F_{10}=13.927\right)$. More importantly, extreme support was found for the interaction between these factors $\left(B F_{10}=2454.720\right)$. Bayesian MannWhitney tests were carried out to analyze this interaction (under the hypothesis of greater distraction in older than in young adults). In line with the results reported in the sections above, older adults exhibited greater $\mathrm{PMD}_{R T}$ than young adults $\left(W=4,601, B F_{10}=1127.591\right)$ in cross-modal tasks. In contrast, we found strong support for the absence of a difference between the two age groups in the uni-modal tasks $(W=1,714$, $\left.B F_{10}=0.090\right)$.

\section{DISCUSSION}

Past research suggested that older adults exhibit greater distraction by unexpected sounds than young adults in visual tasks, an effect particularly salient in RT (Andrés et al., 2006; Parmentier and Andrés, 2010; Leiva et al., 2015b, 2016). However, these studies did not control for age-related variations in response speed as a potential explanatory factor (Shimamura, 1994; Salthouse and Meinz, 1995; Salthouse, 1996). We addressed that issue by revisiting these studies using a PMD. The results from the analysis of RT were unambiguous: older adults exhibited greater deviance distraction than young adults when controlling for baseline response speed (in each individual study and in the combined data set). Bayesian estimation revealed a proportional lengthening of RT by unexpected sounds that was about twice as large in older than in young adults ( 0.069 vs. 0.029 , respectively, a statistically large effect). The analysis of the PC produced similar results, though the effect was statistically smaller overall and somewhat variable across studies. Overall, for both dependent measures, aging increased distraction, thereby ruling out a speed-accuracy tradeoff. Finally, an additional analysis confirmed the selective effect of aging on distraction in cross-modal as opposed to unimodal tasks.

The results summarized above bolster the view that aging is associated with a greater sensitivity to distraction by unexpected sounds when participants are performing a visual task. This contrasts with the absence of age-related difference in unimodal oddball studies (Mager et al., 2005; Horváth et al., 2009; Getzmann et al., 2013; Leiva et al., 2015a,b). In these studies, unexpected sounds yielded distraction to similar levels in young and older adults. While the two sets of studies yield divergent findings regarding the impact of aging on distraction, they converge in dismissing general slowing as a key variable. Indeed, uni-modal oddball tasks generated similar results despite diverging with respect to overall age-related differences in response latencies: Two studies observed overall slower responses in older than in young adults (Leiva et al., 2015b), while three did not (Mager et al., 2005; Horváth et al., 2009; Getzmann et al., 2013). Though difficult to pinpoint the factor(s) underpinning 
this discrepancy, it may relate to the more demanding nature of the task used in the first two (parity judgment applied to a set of six possible stimuli) compared to the other three (short/long duration judgment). In any case, the fact that all five studies reported equivalent levels of distraction in the two age groups strongly suggests that distraction was not a function of baseline response speed. Hence, our results and the findings from unimodal studies converge in distinguishing deviance distraction from age-related slowing.

One possible explanation for the selective effect of aging on distraction observed in cross-modal tasks may relate to the nature of the attentional shift entailed by unexpected sounds. Parmentier et al. (2008) suggested that deviance distraction may in part originate from a shift of attention between sensory modalities. That is, the unexpected sound, by virtue of violating sensory predictions, triggers a shift of attention from the visual modality to the auditory modality, and back to the visual modality when the target stimulus is presented. The notion of a time penalty associated with cross-modal attention shifts is consistent with evidence that shifting attention between two stimuli takes longer when these are presented in distinct sensory modalities vs. in the same modality (Turatto et al., 2002, 2004; Shomstein and Yantis, 2004; Rodway, 2005; Miles et al., 2011). Such findings support the reasonable assumption that cross-modal shifts of attention may summon greater control than within-modality shifts and invoke specific higher-levels mechanisms. Furthermore, evidence also indicates that while within-modality shifts appear to mostly mobilize primary sensory cortices, cross-modal shifts involve more extensive frontal networks (Eimer et al., 2001; Talsma et al., 2008; Salmi et al., 2009). For example, some authors have proposed that frontal alpha oscillations reflect the origin of intersensory re-orienting (Misselhorn et al., 2019). Generally, this view fits well with the hierarchical organization of control in the prefrontal cortex (Koechlin et al., 2003; Koechlin and Summerfield, 2007). Of interest, aging is associated with a proportionally greater neural deterioration in prefrontal regions (West, 1996; Raz, 2000) while posterior attentional networks are relatively spared (Greenwood et al., 1993; Hartley, 1993). Hence, we posit that the locus of the age difference in distraction by unexpected sounds in visual oddball tasks may lie in the selective alteration of frontal networks underpinning the control of attention across sensory modalities. The proposition that the effect of aging unravels in relatively late stages of processing, after the initial detection of change, fits well with EEG findings indicating that aging does not modulate early markers of the orienting response in active tasks (Berti et al., 2017).

\section{REFERENCES}

Ahveninen, J., Jaaskelainen, I. P., Pekkonen, E., Hallberg, A., Hietanen, M., Näätänen, R., et al. (2000). Increased distractibility by task-irrelevant sound changes in abstinent alcoholics. Alcoh. Clin. Exper. Res. 24, 1850-1854. doi: 10.1111/j.1530-0277.2000.tb01989.x

Andrés, P., Parmentier, F. B. R., and Escera, C. (2006). The effect of age on involuntary capture of attention by irrelevant sounds: a test of the frontal hypothesis of aging. Neuropsychologia 44, 2564-2568. doi: 10.1016/j. neuropsychologia.2006.05.005

\section{CONCLUSION}

In conclusion, our study provided evidence that distraction by unexpected sounds in visual tasks is greater in older than in young adults, and that this effect cannot be accounted by variations in baseline performance between the two age groups. The results of Bayesian estimation indicate that the proportional lengthening of RT following an unexpected sound is about twice as large for older than for young adults. Interpreted in a wider context, our results point to differences in the mechanisms underpinning cross-modal shifts of attention as the possible locus of the age-related effect.

\section{DATA AVAILABILITY STATEMENT}

Publicly available datasets were analyzed in this study. This data can be found here: https://osf.io/78vk5.

\section{ETHICS STATEMENT}

The studies involving human participants were reviewed and approved by the Balearic Islands Bioethics Review Board. The patients/participants provided their written informed consent to participate in this study.

\section{AUTHOR CONTRIBUTIONS}

AL carried out the data collection. FP performed the statistical analysis. FP wrote the first draft of the manuscript, with contributions from AL and PA. All authors contributed to the conception and design of this study, and approved the submitted version.

\section{FUNDING}

This research was supported by two research grants (PSI201454261-P and PSI2016-75484-R) from the Spanish Ministry of Science, Innovation, and Universities, the Spanish State Agency for Research (AEI), and the European Regional Development Fund (FEDER). FP's contract at the University of the Balearic Islands was co-financed by the Spanish Ministry of Science, Innovation and Universities through their program for the incentivization and permanent incorporation of doctors (IEDI2016-00742).

Bendixen, A., Grimm, S., Deouell, L. Y., Wetzel, N., Maedebach, A., and Schröger, E. (2010). The time-course of auditory and visual distraction effects in a new crossmodal paradigm. Neuropsychologia 48, 2130-2139. doi: 10.1016/j. neuropsychologia.2010.04.004

Berti, S. (2008). Cognitive control after distraction: event-related brain potentials (ERPs) dissociate between different processes of attentional allocation. Psychophysiology 45, 608-620. doi: 10.1111/j.1469-8986.2008.00660.x

Berti, S. (2013). The role of auditory transient and deviance processing in distraction of task performance: a combined behavioral and event-related brain potential study. Front. Hum. Neurosci. 7:352. doi: 10.3389/fnhum.2013.00352 
Berti, S., Grunwald, M., and Schröger, E. (2013). Age dependent changes of distractibility and reorienting of attention revisited: an event-related potential study. Brain Res. 1491, 156-166. doi: 10.1016/j.brainres.2012.11.009

Berti, S., and Schröger, E. (2001). A comparison of auditory and visual distraction effects: behavioral and event-related indices. Cogn. Brain Res. 10, 265-273. doi: 10.1016/S0926-6410(00)00044-6

Berti, S., Vossel, G., and Gamer, M. (2017). The orienting response in healthy aging: novelty P3 indicates no general decline but reduced efficacy for fast stimulation rates. Front. Psychol. 8:1780. doi: 10.3389/fpsyg.2017.01780

Cerella, J. (1985). Information processing rates in the elderly. Psychol. Bull. 98, 67-83. doi: 10.1037/0033-2909.98.1.67

Cohen, J. (1988). Statistical Power Analysis for the Behavioral Sciences, 2nd Edn, New York, NY: Routledge, doi: 10.4324/9780203771587

Corbetta, M., and Shulman, G. L. (2002). Control of goal-directed and stimulusdriven attention in the brain. Nat. Rev. Neurosci. 3, 201-215. doi: 10.1038/ nrn755

Dienes, Z. (2014). Using Bayes to get the most out of non-significant results. Front. Psychol. 5:781. doi: 10.3389/fpsyg.2014.00781

Eimer, M., Cockburn, D., Smedley, B., and Driver, J. (2001). Cross-modal links in endogenous spatial attention are mediated by common external locations: evidence from event-related brain potentials. Exper. Brain Res. 139, 398-411. doi: $10.1007 / \mathrm{s} 002210100773$

Escera, C., Alho, K., Winkler, I., and Näätänen, R. (1998). Neural mechanisms of involuntary attention to acoustic novelty and change. J. Cogn. Neurosci. 10, 590-604. doi: 10.1162/089892998562997

Getzmann, S., Gajewski, P. D., and Falkenstein, M. (2013). Does age increase auditory distraction? electrophysiological correlates of high and low performance in seniors. Neurobiol. Aging 34, 1952-1962. doi: 10.1016/j. neurobiolaging.2013.02.014

Greenwood, P. M., Parasuraman, R., and Haxby, J. V. (1993). Changes in visuospatial attention over the adult life-span. Neuropsychologia 31, 471-485. doi: 10.1016/0028-3932(93)90061-4

Hartley, A. A. (1993). Evidence for the selective preservation of spatial selective attention in old-age. Psychol. Aging 8, 371-379. doi: 10.1037/0882-7974.8.3.371

Horváth, J., and Bendixen, A. (2012). Preventing distraction by probabilistic cueing. Intern. J. Psychophysiol. 83, 342-347. doi: 10.1016/j.ijpsycho.2011.11. 019

Horváth, J., Czigler, I. I., Birkás, E., Winkler, I. I., and Gervai, J. (2009). Age-related differences in distraction and reorientation in an auditory task. Neurobiol. Aging 30, 1157-1172. doi: 10.1016/j.neurobiolaging.2007.10.003

Horváth, J., Winkler, I., and Bendixen, A. (2008). Do N1/MMN, P3a, and RON form a strongly coupled chain reflecting the three stages of auditory distraction? Biol. Psychol. 79, 139-147. doi: 10.1016/j.biopsycho.2008.04.001

Hughes, R. W., Vachon, F., and Jones, D. M. (2005). Auditory attentional capture during serial recall: violations at encoding of an algorithm-based neural model? J. Exper. Psychol. Learn. Mem. Cogn. 31, 736-749.

JASP Team (2019). JASP (Version 0.10.1) [Computer Software]. Amsterdam: JASP Team.

Jeffreys, H. (1961). Theory of Probability, 3rd Edn, Oxford: Oxford University Press.

Koechlin, E., Ody, C., and Kouneiher, F. (2003). The architecture of cognitive control in the human prefrontal cortex. Science 302, 1181-1185. doi: 10.1126/ science. 1088545

Koechlin, E., and Summerfield, C. (2007). An information theoretical approach to prefrontal executive function. Trends Cogn. Sci. 11, 229-235. doi: 10.1016/j.tics. 2007.04.005

Körner, U., Röer, J. P., Buchner, A., and Bell, R. (2017). Working memory capacity is equally unrelated to auditory distraction by changing-state and deviant sounds. J. Mem. Lang. 96, 122-137. doi: 10.1016/j.jml.2017.05.005

Kruschke, J. K. (2011). Bayesian assessment of null values via parameter estimation and model comparison. Perspect. Psychol. Sci. 6, 299-312. doi: 10.1177/ 1745691611406925

Kruschke, J. K. (2013). Bayesian estimation supersedes the t test. J. Exper. Psychol. Gen. 142, 573-603. doi: 10.1037/a0029146

Kruschke, J. K. (2015). Doing Bayesian Data Analysis: A Tutorial With R, JAGS, and Stan, 2nd Edn. Amsterdam: Elsevier.

Kruschke, J. K. (2018). Rejecting or accepting parameter values in Bayesian estimation. Adv. Methods Pract. Psychol. Sci. 1, 270-280. doi: 10.1177/ 2515245918771304

Kruschke, J. K., and Liddell, T. M. (2018). The Bayesian new statistics: hypothesis testing, estimation, meta-analysis, and power analysis from a
Bayesian perspective. Psychon. Bull. Rev. 25, 178-206. doi: 10.3758/s13423-0161221-4

Kruschke, J. K., and Meredith, M. (2018). Bayesian Estimation Supersedes the t-Test (0.5.1). Available online at: https://cran.r-project.org/package=BEST

Lakens, D. (2013). Calculating and reporting effect sizes to facilitate cumulative science: a practical primer for t-tests and ANOVAs. Front. Psychol. 4:863. doi: 10.3389/fpsyg.2013.00863

Lee, M. D., and Wagenmakers, E. J. (2013). Bayesian Cognitive Modeling: A Practical Course. Cambridge, MA: Cambridge University Press, doi: 10.1017/ CBO9781139087759

Leiva, A., Andrés, P., and Parmentier, F. B. R. (2015a). When aging does not increase distraction: evidence from pure auditory and visual oddball tasks. J. Exper. Psychol. Hum. Percept. Perform. 41, 1612-1622. doi: 10.1037/ xhp0000112

Leiva, A., Parmentier, F. B. R., and Andrés, P. (2015b). Aging increases distraction by auditory oddballs in visual, but not auditory tasks. Psychol. Res. Psychol. Forschung 79, 401-410. doi: 10.1007/s00426-014-0573-5

Leiva, A., Andrés, P., Servera, M., Verbruggen, F., and Parmentier, F. B. R. (2016). The role of age, working memory, and response inhibition in deviance distraction: a cross-sectional study. Dev. Psychol. 52, 1381-1393. doi: 10.1037/ dev0000163

Li, B., Parmentier, F. B. R., and Zhang, M. (2013). Behavioral distraction by auditory deviance is mediated by the sound's informational value: evidence from an auditory discrimination task. Exper. Psychol. 60, 260-268. doi: 10.1027/1618$3169 / \mathrm{a} 000196$

Mager, R., Falkenstein, M., Störmer, R., Brand, S., Müller-Spahn, F., and Bullinger, A. H. (2005). Auditory distraction in young and middle-aged adults: a behavioural and event-related potential study. J. Neural Transm. 112, 11651176. doi: 10.1007/s00702-004-0258-0

Miles, E., Brown, R., and Poliakoff, E. (2011). Investigating the nature and timecourse of the modality shift effect between vision and touch. Q. J. Exper. Psychol. 64, 871-888. doi: 10.1080/17470218.2010.514054

Misselhorn, J., Friese, U., and Engel, A. K. (2019). Frontal and parietal alpha oscillations reflect attentional modulation of cross-modal matching. Sci. Rep. 9:5030. doi: 10.1038/s41598-019-41636-w

Pacheco-Unguetti, A. P., and Parmentier, F. B. R. (2014). Sadness increases distraction by auditory deviant stimuli. Emotion 14, 203-213. doi: 10.1037/ a0034289

Pacheco-Unguetti, A. P., and Parmentier, F. B. R. (2016). Happiness increases distraction by auditory deviant stimuli. Br. J. Psychol. 107, 419-433. doi: 10. 1111/bjop. 12148

Parmentier, F. B. R. (2014). The cognitive determinants of behavioral distraction by deviant auditory stimuli: a review. Psychol. Res. 78, 321-338. doi: 10.1007/ s00426-013-0534-4

Parmentier, F. B. R. (2016). Deviant sounds yield distraction irrespective of the sounds' informational value. J. Exper. Psychol. Hum. Percept. Perform. 42, 837-846. doi: 10.1037/xhp0000195

Parmentier, F. B. R., and Andrés, P. (2010). The involuntary capture of attention by sound novelty and postnovelty distraction in young and older adults. Exper. Psychol. 57, 68-76. doi: 10.1027/1618-3169/a000009

Parmentier, F. B. R., Elford, G., Escera, C., Andrés, P., and Miguel, I. S. (2008). The cognitive locus of distraction by acoustic novelty in the cross-modal oddball task. Cognition 106, 408-432. doi: 10.1016/j.cognition.2007.03.008

Parmentier, F. B. R., Elsley, J. V., Andrés, P., and Barceló, F. (2011). Why are auditory novels distracting? Contrasting the roles of novelty, violation of expectation and stimulus change. Cognition 119, 374-380. doi: 10.1016/j. cognition.2011.02.001

Parmentier, F. B. R., and Gallego, L. (2020). Is deviance distraction immune to the prior sequential learning of stimuli and responses? Psychon. Bull. Rev. 27, 490-497. doi: 10.3758/s13423-020-01717-8

Parmentier, F. B. R., and Hebrero, M. (2013). Cognitive control of involuntary distraction by deviant sounds. J. Exper. Psychol. Learn. Mem. Cogn. 39, 16351641. doi: $10.1037 / \mathrm{a} 0032421$

Parmentier, F. B. R., Turner, J., and Perez, L. (2014). A dual contribution to the involuntary semantic processing of unexpected spoken words. J. Exper. Psychol. Gen. 143, 38-45. doi: 10.1037/a0031550

Parmentier, F. B. R., Vasilev, M. R., and Andrés, P. (2018). Surprise as an explanation to auditory novelty distraction and post-error slowing. J. Exper. Psychol. Gen. 148, 192-200. doi: 10.1037/xge000 0497 
Patil, I. (2021). Visualizations with statistical details: the "ggstatsplot" approach. PsyArxiv [Preprint]. doi: 10.31234/osf.io/p7mku

Quintana, D. S., and Williams, D. R. (2018). Bayesian alternatives for common null-hypothesis significance tests in psychiatry: a non-technical guide using JASP. BMC Psychiatry 18:178. doi: 10.1186/s12888-018$1761-4$

R Core Team (2021). R: A Language and Environment for Statistical Computing. Vienna: R Core Team.

Raz, N. (2000). "Aging of the brain and its impact on cognitive performance: integration of structural and functional finding," in Handbook of Aging and Cognition, eds F. I. M. Craik and T. A. Salthouse (Mahwah, NJ: Erlbaum), 1-90.

Rodway, P. (2005). The modality shift effect and the effectiveness of warning signals in different modalities. Acta Psychol. 120, 199-226. doi: 10.1016/j.actpsy.2005. 05.002

Roeber, U., Widmann, A., and Schröger, E. (2003). Auditory distraction by duration and location deviants: a behavioral and event-related potential study. Cogn. Brain Res. 17, 347-357. doi: 10.1016/S0926-6410(03)00136-8

Röer, J. P., Bell, R., Körner, U., and Buchner, A. (2018). Equivalent auditory distraction in children and adults. J. Exper. Child Psychol. 172, 41-58. doi: 10.1016/j.jecp.2018.02.005

Röer, J. P., Bell, R., Marsh, J. E., and Buchner, A. (2015). Age equivalence in auditory distraction by changing and deviant speech sounds. Psychol. Aging 30, 849-855. doi: 10.1037/pag0000055

Röer, J. P., Körner, U., Buchner, A., and Bell, R. (2017). Attentional capture by taboo words: a functional view of auditory distraction. Emotion 17, 740-750. doi: 10.1037/emo0000274

Rogers, W. A., and Fisk, A. D. (1990). A reconsideration of age-related reaction time slowing from a learning perspective: age-related slowing is not just complexity-based. Learn. Individ. Differ. 2, 161-179. doi: 10.1016/10416080(90)90021-8

Rosburg, T., Weigl, M., Thiel, R., and Mager, R. (2018). The event-related potential component P3a is diminished by identical deviance repetition, but not by nonidentical repetitions. Exper. Brain Res. 236, 1519-1530. doi: 10.1007/s00221$018-5237-\mathrm{z}$

Salmi, J., Rinne, T., Koistinen, S., Salonen, O., and Alho, K. (2009). Brain networks of bottom-up triggered and top-down controlled shifting of auditory attention. Brain Res. 1286, 155-164. doi: 10.1016/j.brainres.2009. 06.083

Salthouse, T. A. (1996). The processing-speed theory of adult age differences in cognition. Psychol. Rev. 103, 403-428. doi: 10.1037/0033-295x.103.3.403

Salthouse, T. A. (2000). "Steps toward the explanation of adult age differences in cognition," in Models of Cognitive Aging, eds T. J. Perfect and E. A. Maylor (Oxford: Oxford University Press), 19-49.

Salthouse, T. A., and Meinz, E. J. (1995). Aging, inhibition, working memory, and speed. J. Gerontol. Ser. B Psychol. Sci. Soc. Sci. 50, 297-306. doi: 10.1093/geronb/ 50B.6.P297

Schröger, E. (1996). A neural mechanism for involuntary attention shifts to changes in auditory stimulation. J. Cogn. Neurosci. 8, 527-539. doi: 10.1162/jocn.1996.8. 6.527

Schröger, E. (2005). The mismatch negativity as a tool to study auditory processing. Acta Acust. 91, 490-501.

Schröger, E. (2007). Mismatch negativity - a microphone into auditory memory. J. Psychophysiol. 21, 138-146. doi: 10.1027/0269-8803.21.34.138

Schröger, E., Bendixen, A., Trujillo-Barreto, N. J., and Roeber, U. (2007). Processing of abstract rule violations in audition. PLoS One 2:e001131. doi: 10.1371/ journal.pone.0001131

Schröger, E., and Roeber, U. (2021). Encoding of deterministic and stochastic auditory rules in the human brain: the mismatch negativity mechanism does not reflect basic probability. Hear. Res. 399:107907. doi: 10.1016/j.heares.2020. 107907

Schröger, E., and Wolff, C. (1998). Behavioral and electrophysiological effects of task-irrelevant sound change: a new distraction paradigm. Cogn. Brain Res. 7 , 71-87. doi: 10.1016/S0926-6410(98)00013-5

Shimamura, A. P. (1994). Neuropsychological perspectives on memory and cognitive decline in normal human aging. Semin. Neurosci. 6, 387-394. doi: 10.1006/smns.1994.1050

Shomstein, S., and Yantis, S. (2004). Control of attention shifts between vision and audition in human cortex. J. Neurosci. 24, 10702-10706. doi: 10.1523/ JNEUROSCI.2939-04.2004
Sussman, E., Winkler, I., and Schröger, E. (2003). Top-down control over involuntary attention switching in the auditory modality. Psychon. Bull. Rev. 10, 630-637. doi: 10.3758/bf03196525

Talsma, D., Kok, A., Slagter, H. A., and Cipriani, G. (2008). Attentional orienting across the sensory modalities. Brain Cogn. 66, 1-10. doi: 10.1016/j.bandc.2007. 04.005

Turatto, M., Benso, F., Galfano, G., and Umilta, C. (2002). Nonspatial attentional shifts between audition and vision. J. Exper. Psychol. Hum. Percept. Perform. 28, 628-639. doi: 10.1037//0096-1523.28.3.628

Turatto, M., Galfano, G., Bridgeman, B., Umilta, C., and Umiltà, C. (2004). Spaceindependent modality-driven attentional capture in auditory, tactile and visual systems. Exper. Brain Res. 155, 301-310. doi: 10.1007/s00221-003-1724-x

Vachon, F., Labonté, K., and Marsh, J. E. (2017). Attentional capture by deviant sounds: a noncontingent form of auditory distraction? J. Exper. Psychol. Learn. Mem. Cogn. 43, 622-634. doi: 10.1037/xlm0000330

Vasilev, M. R., Parmentier, F. B. R., Angele, B., and Kirkby, J. A. (2019). Distraction by deviant sounds during reading: an eye-movement study. Q. J. Exper. Psychol. 72, 1863-1875. doi: $10.1177 / 1747021818820816$

Vasilev, M. R., Parmentier, F. B. R., and Kirkby, J. A. (2021). Distraction by auditory novelty during reading: evidence for disruption in saccade planning, but not saccade execution. Q. J. Exper. Psychol. 74, 826-842. doi: 10.1177/ 1747021820982267

Verbruggen, F., McLaren, I. P. L., and Chambers, C. D. (2014). Banishing the control homunculi in studies of action control and behavior change. Perspect. Psychol. Sci. 9, 497-524. doi: 10.1177/1745691614526414

Volosin, M., Gaál, Z. A., and Horváth, J. (2017). Task-optimal auditory attention set restored as fast in older as in younger adults after distraction. Biol. Psychol. 126, 71-81. doi: 10.1016/j.biopsycho.2017.04.007

Volosin, M., and Horváth, J. (2014). Knowledge of sequence structure prevents auditory distraction: an ERP study. Intern. J. Psychophysiol. 92, 93-98. doi: 10.1016/j.ijpsycho.2014.03.003

Volosin, M., and Horváth, J. (2020). Task difficulty modulates voluntary attention allocation, but not distraction in an auditory distraction paradigm. Brain Res. 1727:146565. doi: 10.1016/j.brainres.2019.146565

Wessel, J. R. (2017). Perceptual surprise aides inhibitory motor control. J. Exper. Psychol. Hum. Percept. Perform. 43, 1585-1593. doi: 10.1037/xhp0000452

Wessel, J. R., and Aron, A. R. (2013). Unexpected events induce motor slowing via a brain mechanism for action-stopping with global suppressive effects. J. Neurosci. 33, 18481-18491. doi: 10.1523/jneurosci.3456-13.2013

Wessel, J. R., and Aron, A. R. (2017). On the globality of motor suppression: unexpected events and their influence on behavior and cognition. Neuron 93 , 259-280. doi: 10.1016/j.neuron.2016.12.013

Wessel, J. R., and Huber, D. E. (2019). Frontal cortex tracks surprise separately for different sensory modalities but engages a common inhibitory control mechanism. PLoS Computat. Biol. 15:e1006927. doi: 10.1371/journal.pcbi. 1006927

West, R. L. (1996). An application of prefrontal cortex function theory to cognitive aging. Psychol. Bull. 120, 272-292. doi: 10.1037/0033-2909.120.2.272

Wickham, H. (2016). ggplot2: Elegant Graphics for Data Analysis. New York, NY: Springer-Verlag.

Winkler, I. (2007). Interpreting the mismatch negativity. J. Psychophysiol. 21, 147-163. doi: 10.1027/0269-8803.21.34.147

Conflict of Interest: The authors declare that the research was conducted in the absence of any commercial or financial relationships that could be construed as a potential conflict of interest.

Publisher's Note: All claims expressed in this article are solely those of the authors and do not necessarily represent those of their affiliated organizations, or those of the publisher, the editors and the reviewers. Any product that may be evaluated in this article, or claim that may be made by its manufacturer, is not guaranteed or endorsed by the publisher.

Copyright (c) 2021 Leiva, Andrés and Parmentier. This is an open-access article distributed under the terms of the Creative Commons Attribution License (CC BY). The use, distribution or reproduction in other forums is permitted, provided the original author(s) and the copyright owner(s) are credited and that the original publication in this journal is cited, in accordance with accepted academic practice. No use, distribution or reproduction is permitted which does not comply with these terms. 